\title{
The humane collection of fetal bovine serum and possibilities for serum-free cell and tissue culture
}

\author{
J. van der Valk ${ }^{\mathrm{a}, *}$, D. Mellor ${ }^{\mathrm{b}}$, R. Brands ${ }^{\mathrm{c}}$, R. Fischer ${ }^{\mathrm{d}}$, F. Gruber ${ }^{\mathrm{e}}$, G. Gstraunthaler ${ }^{\mathrm{f}}$, \\ L. Hellebrekers' ${ }^{g}$, J. Hyllner ${ }^{h}$, F.H. Jonker ${ }^{\mathrm{i}}$, P. Prieto ${ }^{\mathrm{j}}$, M. Thalen ${ }^{\mathrm{k}}$, V. Baumans ${ }^{1, \mathrm{~m}}$ \\ ${ }^{a}$ Netherlands Centre Alternatives to Animal Use (NCA) Centre For Animals and Society, Fac. Veterinary Medicine, Utrecht University, Yalelaan 17, Utrecht \\ NL-3584 CL, The Netherlands \\ ${ }^{\mathrm{b}}$ Animal Welfare Science and Bioethics Centre (IFNHH), Massey University, Palmerston North, New Zealand \\ ${ }^{\mathrm{c}}$ AM-Pharma, division PharmaAAware, Rumpsterweg 6, Bunnik NL-3981 AK, The Netherlands \\ ${ }^{\mathrm{d}}$ ETH Hoenggerberg, Laboratorium fuer Organische Chemie, Wolfgang Pauli Strasse, CH-8093 Zurich, Switzerland \\ ${ }^{\mathrm{e}}$ FFVFF, Hegarstr. 9, CH-8032 Zurich, Switzerland \\ ${ }_{\mathrm{f}}^{\mathrm{f}}$ Institute of Physiology, University of Innsbruck, Fritz-Pregl-Strasse 3, A-6010 Innsbruck, Austria \\ ${ }^{\mathrm{g}}$ Anaesthesiology Section, Dept. of Equine Sciences and Dept. Clinical Sciences of Companion Animals, Fac. Veterinary Medicine, Utrecht University, \\ Yalelaan 12, 3508 TD, Utrecht, The Netherlands \\ ${ }^{\mathrm{h}}$ Cell Therapeutics Scandinavia AB, Medicinaregatan 8A, SE-413 46 Göteborg, Sweden \\ iDepartment of Farm Animal Health, Fac. Veterinary Medicine, Utrecht University, Yalelaan 7, Utrecht NL-3584 CL, The Netherlands \\ ${ }^{\mathrm{j}}$ ECVAM, Institute for Health \& Consumer Protection, Joint Research Centre, European Commission, 21020 Ispra (Va), Italy \\ ${ }^{\mathrm{k}}$ Laboratory for Process and Product Development, P.O. Box 457, Netherlands Vaccine Institute, Bilthoven, NL-3720 AL, The Netherlands \\ ${ }^{1}$ Dept. of Laboratory Animal Science, Fac. Veterinary Medicine, Utrecht University, Yalelaan 2, Utrecht NL-3508 TD, The Netherlands \\ ${ }^{\mathrm{m}}$ Karolinska Institute, Stockholm, Sweden
}

\begin{abstract}
Fetal bovine serum (FBS) is a common supplement to in vitro culture media. A workshop was organized to discuss whether or not fetuses might suffer when blood is withdrawn, and to discuss serum replacement methods. When bovine fetuses are exposed after slaughter of the dam, they can suffer only if they inflate their lungs with air and increase their blood oxygen to levels compatible with awareness. Preventing fetuses from breathing air or killing them by an efficient method, according to clearly defined safeguards, ensures that fetal blood collection is humane. Since serum is a supplement of unknown composition, which could be contaminated with unwanted factors, there are scientific and safety reasons for omitting FBS from culture media. Several media have been developed in which minimal or no animal derived components are present. Also, different cell types have been adapted to serum-free media. As yet, no standard serum free media are present, and each cell type requires its own medium composition. Among other recommendations, the establishment of a public database with information on cell types and their serumfree medium composition is proposed.
\end{abstract}

(C) 2003 Elsevier Ltd. All rights reserved.

\section{Introduction}

The workshop "Towards Better In Vitro Methods, The Replacement of Fetal Bovine Serum" took place from 5 to 7 April, 2003 at Hotel Mitland in Utrecht, The Netherlands. It was organised by Vera Baumans and Jan van der Valk to discuss the conclusions of the report "Use, trade and harvest of livestock sera" (Jochems, 1997). Participants were experts in the field of

\footnotetext{
* Corresponding author. Tel.: + 31-30-253-2163; fax: +31-30-253-

E-mail address: valk@las.vet.uu.nl (J.van der Valk).
} 9227. (fetal) pain and awareness and serum-free in vitro methods. The workshop was made possible by the generous support of the Netherlands Organization for Health Research and Development (ZonMw), the Swedish National Board for Laboratory Animals (CFN) and the European Society for Toxicology In Vitro (ESTIV).

In vitro cell, tissue and organ cultures play an important role in science, medicine and industry. Fetal Bovine Serum (FBS) is a common supplement to in vitro and ex vivo cell, tissue and organ cultures. It contains essential components such as hormones, vitamins, transport proteins and attachment, spreading and growth factors 
(Maurer, 1986). It is estimated that about 500,000 litres of serum are produced on an annual basis (Hodgson, 1995). For this purpose more than $1,000,000$ bovine fetuses have to be harvested annually (Jochems et al., 2002). Use of FBS is expected to increase in the coming years, due to an increase in the development and use of in vitro methods, such as in vitro fertilization, cloning, in vitro toxicity testing and the creation of genetically modified animals. Also, the European Commission's "White paper on a strategy for a future chemicals policy" (Anon, 2001) may lead to an increased use of in vitro methods (Worth and Balls, 2002). The replacement of animals by in vitro methods in biomedical research is a favourable development and meets the Three Rs initiatives, designed to replace, reduce and/or refine animal experiments in teaching, research and testing (Balls et al., 1995; Russell and Burch, 1959).

However, the use of FBS may involve both moral and scientific problems. Concerns have been raised that the current ways of collecting FBS may cause suffering to the animals, in particular to fetuses (Jochems, 1997; Jochems et al., 2002; Kohlpoth and Rusche, 1997).

With regard to scientific problems: the composition of FBS is unknown and varies between batches, and FBS may be contaminated with viruses, mycoplasms and prions. This may interfere with the reproducibility of experiments and the safety of products (Eloit, 1999; Shah, 1999; Wessman and Levings, 1999). Because of the safety risks, regulatory authorities discourage or prohibit the use of animal sera and other components for the production of biological products for human use (Asher, 1999).

Since in vitro methods have been and are being developed as alternatives to animal experiments, the use of FBS seems to be contradictory in some ways to the purposes of the Three Rs concept (Russell and Burch, 1959). It may therefore be questioned whether it is ethically and scientifically justified to use this supplement with the aim of replacing and reducing animal use in teaching, research and testing.

During the workshop, the possibility that the fetus might suffer during serum harvesting by different methods was discussed. Furthermore, the possibilities for using serum-free media were explored.

\section{The welfare of fetal calves during blood (serum) collection}

Collection of fetal calf blood (serum) occurs in some meat processing plants after the pregnant uterus has been removed from the slaughtered cow at the evisceration stage, which in different countries occurs at different times after the neck cut of the dam. It can occur as early as $5 \mathrm{~min}$ or as long as $25-40 \mathrm{~min}$ or more after slaughter of the cow (Jochems et al., 2002; Mellor and
Gregory, 2003). Blood collection methods involve significant manipulation of the fetus, which in some cases may be suspended from an A-frame with application of an external device that simulates the pumping action of the heart while blood is drained from catheterised umbilical vessels, or the methods may be more invasive, involving insertion of a $12-16$ gauge needle between the $4^{\text {th }}$ and $5^{\text {th }}$ rib into the fetal heart. Whatever the method used, if the fetus were to be aware (conscious) during the conduct of such procedures there is potential for it to experience significant pain and/or distress. This raises the issue of whether the fetus is likely to be aware, and if it is, what safeguards could be put in place to minimise any suffering it might experience during the blood collection procedure.

\subsection{The potential for fetal awareness}

Opinions are divided on the issue of fetal awareness. Although suppressors of fetal behavioural arousal and awareness are known to operate before birth, at present there is general agreement that it is not possible to state definitively that during normal development the ruminant fetus never experiences awareness (Mellor and Gregory, 2003). Accordingly, it is necessary, ethically, to consider what would be the consequences of fetal awareness. This is because awareness in higher animals, whether adult or juvenile, confers on them the potential to experience pain and distress, and thereby to suffer. Unaware (unconscious) or dead animals cannot have noxious experiences and therefore cannot suffer.

Fetal age or maturity has some bearing on when a fetus might become aware (Mellor and Gregory, 2003). Awareness of sensations by the fetus requires that its peripheral sensory apparatus be connected to the higher centres of its brain and that the maturity of its brain function be such that it could sustain awareness. The former is reasonably well documented as being well advanced in sheep once $70 \%$ of gestation has elapsed (Mellor and Gregory, 2003), but the latter remains problematical. However, the establishment of discrete fetal sleep states, identified by distinct electroencephalographic (EEG) or electrocorticographic (ECoG) patterns and electro-ocular activity, between $75 \%$ and $85 \%$ gestation in sheep and other species, is said to indicate that major neural interconnections and integrating cerebral activities have matured (Berger et al., 1986; Clewlow et al., 1983; Dawes, 1988; Dawes et al., 1972; Harding et al., 1981). Further development of cerebral processes is indicated by the appearance of the distinct state of fetal behavioural arousal, identified by low voltage EEG/ECoG activity and increases in postural muscle activity, electro-ocular activity, breathing rate and responsiveness to stimulation, which is evident from about $80 \%$ of gestation in sheep fetuses (Clewlow et al., 1983; Harding et al., 1981; Rigatto et al., 1988). 
Accordingly, we suggest that fetal awareness, if it exists, may require neural development to have progressed to at least the first of these stages, and would therefore not be likely to appear before about $70 \%$ of gestation has elapsed.

Although the fetus is known to respond physically (e.g. flinching, withdrawal movements) to potentially painful stimuli well before this stage of gestation (Mellor and Gregory, 2003), it is important to note that responsiveness to stimuli, whether noxious or not, is not definitive evidence that a fetus is aware. However, the absence of a response to noxious stimulation in situations where paralytic or other such agents have not been used may be taken as evidence that the fetus is not aware of the applied stimuli.

It follows from the above observations that fetal calves may have the potential to be aware and therefore to suffer if exposed to noxious stimulation after $70 \%$ of gestation has elapsed. As bovine fetal blood is collected at any stage during the last two-thirds of gestation (Jochems et al., 2002), a significant proportion of fetuses may not have the potential to suffer during the process, but equally, a significant proportion representing the larger mature fetuses that yield more blood (Jochems et al., 2002), would have the potential to suffer. The gestational age is not usually known at the time of commercial slaughter so that differentiating on the basis of maturity is not practically feasible. Accordingly, safeguards devised to minimise any suffering fetal calves may experience during this process should be applied to all dams without reference to their stage of pregnancy. This has the further advantage that the estimated stage of $70 \%$ of gestation for the onset of fetal suffering, if it can occur at all, would not be critical, and any such suffering that younger fetuses might experience would also be prevented.

\subsection{Potential sources of fetal suffering}

At slaughter, the neck or chest cut in the dam is designed to cause a catastrophic decrease in the supply of blood to its brain. In sheep, about $50 \%$ of all blood lost at slaughter is lost during the first 10 seconds after the cut, by which time arterial blood pressure is too low for bruise formation (Gregory and Wilkins, 1984). This indicates that utero-placental perfusion would cease near this time leading to cessation of oxygen supply to the fetus (Mellor and Gregory, 2003). Associated with this will be a rapid flattening of fetal EEG/ECoG activity (i.e. progression to an isoelectric state), because EEG/ECoG activity in fetal sheep flattens within $1 \mathrm{~min}$ of occluding the umbilical cord in utero (Mallard et al., 1992), and stopping utero-placental blood flow is likely to have very similar effects. As the rapidity of blood loss (Warriss, 1984) and the speed of flattening of the EEG/ ECoG (Bager et al., 1992; Gregory and Wotton, 1984;
Newhook and Blackmore, 1982) are similar in calves and sheep after an effective neck cut at slaughter, and as neurological responses of fetal calves and sheep to umbilical cord occlusion and to hypoxia and anoxia are likely to be similar, the EEG/ECoG of fetal calves at slaughter of their dams will probably become flat equally rapidly.

It should be noted that human beings with a flat (isoelectric) EEG show no clinical signs of awareness (Gregory, 1998), and that in adult and juvenile animals a flat EEG is taken as definitive evidence of unawareness (unconsciousness) after slaughter (Bager et al., 1992; Gregory, 1998; Newhook and Blackmore, 1982; UFAW, 1987), during unconsciousness under deep anaesthesia with some agents and ultimately during euthanasia (Bager et al., 1992; Karasawa et al., 2001; Luft et al., 2002).

It follows from the above observations that the fetus cannot suffer if invasive procedures only occur after the fetal EEG/ECoG has become flat and provided that precautions are taken to ensure that the EEG/ECoG remains flat. Also, fetal suffering will be absent when other steps are taken to ensure that fetal brain function is sufficiently disordered to be incompatible with awareness.

\subsection{Safeguards}

Adherence to the following safeguards will help to ensure that calf fetuses will not suffer during the collection of their blood (serum) after slaughter of their dams.

First, the fetus must be unaware (unconscious) before any invasive procedure is initiated by the act of cutting open the uterus to expose a part or the whole of the fetus. The EEG/ECoG must therefore be flat before the procedure begins. Although, as noted above, the EEG/ ECoG would be expected to be flat by about $1 \mathrm{~min}$ after the neck cut in the dam, it would be prudent to allow a reasonable safety margin, and not initiate the procedure at that point. This is to allow for variation between dams in bleed-out time (Bager et al., 1992; Gregory, 1998; Levinger, 1995; Newhook and Blackmore, 1982; UFAW, 1987) and for a possible slower onset of a flat $\mathrm{EEG} / \mathrm{ECoG}$ in younger fetuses.

Safeguard 1: The procedure of fetal blood collection must not begin until at least 5 min after an effective neck cut has been completed in the dam (Mellor, 2003; Mellor and Gregory, 2003).

Not only must the EEG/ECoG be flat before the procedure begins, it must remain flat throughout the procedure. This means that the fetus must remain severely hypoxic or anoxic throughout the procedure. The fetus therefore must not be allowed to inflate its lungs with air. This is especially the case in near-birth fetuses where lung maturation may have progressed sufficiently to allow inflation with air (Mellor and Gregory, 2003). It is 
worth noting that provided the blood collection procedure is initiated only after the EEG/ECoG has become flat, i.e. after the prescribed waiting time of at least 5 min, the hypovolemia due to blood removal from a living fetus will help to ensure that it remains unaware. Ultimately the combined effects of anoxia and blood loss would lead to fetal death. Fetal death is indicated by an irreversibly flat EEG/ECoG or, if such measurements cannot be made, by the absence of a palpable heartbeat.

Safeguard 2: The fetus must not be allowed to breathe air at any stage after removal of the pregnant uterus from the dam (Mellor, 2003; Mellor and Gregory, 2003). In practice this can be achieved in a living fetus by leaving its head inside the uterus or by clamping its trachea, or by not removing it from the uterus until it is dead (Mellor, 2003; Mellor and Gregory, 2003).

An alternative to preventing living fetuses from breathing air is to guarantee unawareness by taking actions which induce markedly disordered brain function and which rapidly cause death (see Safeguard 3). Such an approach would be required for those fetuses that are exposed before EEG/ECoG flattening is complete.

Safeguard 3: The fetus which may breathe air, or which is exposed before expiry of the 5-minute minimum waiting time after slaughter of the dam, must be stunned with a captive bolt firearm (Jochems et al., 2002) or by a blow to the head with a suitable blunt instrument (Mellor, 2003).

\subsection{Emotional responses to the safeguards}

Killing or otherwise harming fetal, newborn or very young animals is quite challenging emotionally for several reasons, which include their apparent greater vulnerability when compared to adults. Accordingly, some people may be very concerned with the present recommendation that fetal calves must be prevented from breathing air by leaving their heads inside the uterus, clamping their tracheas, or not removing them from the uterus until after they die. This concern may be heightened in cases where such fetal calves are seen to move, as some of them do (Mellor and Gregory, 2003). However, it is important to recall that without awareness suffering is not possible. As the fetal EEG/ECoG has so flattened that no fetal awareness is possible within about 1 minute of slaughter of the dam, the fetus is incapable of suffering at that point, no matter how invasive any procedures applied to it might be. Preventing it from breathing air is designed to ensure that the EEG/ECoG remains flat and that it will therefore remain incapable of suffering until it dies. Accordingly, any movements that occur in such fetuses are initiated by non-conscious activity within the nervous system. Such activity occurs regularly in adult animals soon after slaughter (Gregory, 1998).
Equal concern may be elicited by the recommendation that the fetus be shot in the head with a captive bolt firearm or be given a strong blow to the head with a heavy blunt instrument, but both of these approaches, properly executed, achieve instantaneous unconsciousness or death, and therefore guarantee that suffering is absent.

The point of these recommendations is to safeguard the welfare of the fetus before and during blood collection, and unpleasant as these actions may appear to be, they ensure that no fetal suffering can occur.

\subsection{Blood collection before or after cessation of the heartbeat}

In the absence of breathing air successfully, the fetal heart is likely to keep beating for some minutes after slaughter of the dam, the period generally being longer the younger the fetuses are during the last $40 \%$ of gestation (Mott, 1961). This creates a dilemma.

On the one hand, greater yields of blood are generally obtained by cardiac puncture when the heart is still beating (Jochems, 1997). Thus, more fetal blood would probably be obtained if collection occurs before the fetal heartbeat stops, thereby potentially reducing the total number of fetuses (and their dams) needed to meet the demands for FBS. However, a strict caveat must be applied: blood collection from living fetuses must only be initiated when unawareness is definitely present (i.e. at least 5 min after slaughter of the dam), and when it remains throughout the procedure. Minimising the numbers used in this way would conform to the $3 \mathrm{Rs}$ principle of Reduction, but this would especially apply when animals are bred specifically to meet the international demand for FBS.

On the other hand, commercial pressure to maximise the yield of FBS may lead some producers to ignore the above caveat and begin blood collection before EEG/ ECoG flattening can be assured. This could cause suffering in those fetuses and is considered to be unacceptable on animal welfare grounds. Nor is it necessary. In Australia and New Zealand commercially viable volumes of blood are collected from fetal calves when the procedure begins about 30 to $35 \mathrm{~min}$ after slaughter of the dam, which is a sufficient interval to guarantee an irreversibly flat EEG/ECoG, and, in most fetuses, that there will be no palpable heartbeat (Mellor and Gregory, 2003).

\section{Conclusions}

We conclude that ethical collection of FBS is possible because relatively passive approaches (e.g. wait for hypoxia to become severe enough or prevent breathing) or active approaches (e.g. captive bolt) may be used to ensure that the fetus is unaware (unconscious) before and during collection of its blood. Moreover, however 
challenging their practical implementation may be for some people, the recommended safeguards for calf fetuses are practical and straightforward to put into effect during commercial slaughter of their dams.

The three safeguards noted above represent a Fetal Calf Slaughter Welfare Protocol (Table 1). We recommend that FBS producers be encouraged to adhere to this protocol and that users of FBS ensure that they only purchase it from those producers who demonstrate that they adhere to this protocol.

We have assumed throughout that the method of slaughter of the pregnant dam is humane. For this to be the case, high standards of animal welfare must apply during loading, transport to the processing plant, unloading, lairage while awaiting slaughter, movement to the point of slaughter, pre-slaughter stunning and the act of slaughter itself (Mellor, 2003, Table 1).

\section{Serum-free culturing}

\subsection{Introduction}

The successful in vitro cultivation of mammalian cells of human and/or animal origin but also of insect cells, requires the supplementation of culture media with animal serum of different origin for cell growth and for the stimulation of proliferation ("mitogenic effect"). The sera most widely used are sera of adult or newborn animals, or of fetal bovine origin. Serum, in general, is an extremely complex mixture of a large number of constituents, low and high molecular weight biomolecules with different physiologically balanced growth-promoting and growth-inhibiting activities. Thus, serum introduces an unknown variable into the culture system.

Existing knowledge in modern cell biology and biochemistry allows the identification of (growth) factors involved in in vivo processes, like cell proliferation and tissue repair (e.g. in wound healing), and cell maturation and differentiation (e.g. embryonic maturation, stem cell lineage, epithelial differentiation, etc.). The major functions of serum in culture media are to provide:
1. hormonal factors that stimulate cell growth and proliferation, and promote differentiated functions

2. transport proteins that carry hormones (e.g. transcortin), minerals and trace elements (e.g. transferrin), and lipids (e.g. lipoproteins)

3. attachment and spreading factors (i.e. components of the extracellular matrix), and

4. stabilizing and detoxifying factors, needed to maintain $\mathrm{pH}$ or to inhibit proteases either directly, such as $\alpha$-antitrypsin or $\alpha 2$-macroglobulin, or indirectly, by acting as a non-specific sink for proteases and other (toxic) molecules.

Today, media can be supplemented with a variety of protein sources, which are specific for different cell types. Such protein sources can be:

- Fetal bovine serum

- Human serum

- Bovine serum albumin (BSA)

- Partly purified human albumin (HSA)

- Purified human albumin (HSA, "pharmaceutical quality")

- Recombinant human albumin (r-HSA)

Also, a number of growth factors, hormones, transport proteins, co-factors, essential minerals and trace elements have been described, that all drive specific gene expression, initiate and control the cell cycle and thus cell division, and program specific aspects of cell differentiation. We know today, for example, that a specific transcriptional activation program is needed to initiate cell growth and proliferation in vitro, for instance the specific activation of MAP (mitogen-activated protein) kinases, like the ERK (extracellular signal-regulated kinase) cascade (Kyriakis and Avruch, 2001; Widman et al., 1999), by EGF (epidermal growth factor), FGF (fibroblast growth factor), PDGF (platelet-derived growth factor), and others (Cohen, 1987; Deuel, 1987; Levi-Montalcini, 1987).

The importance of culturing mammalian cells in a medium without serum supplementation is widely

Table 1

Major features of the fetal calf slaughter welfare protocol

1. All features of the presentation of the pregnant dam for slaughter, including loading, transport to the slaughter plant, unloading, lairage, movement to the slaughter point, preslaughter stunning and slaughter itself, must be to high animal welfare standards.

2. Fetal blood collection must not begin until at least 5 min after an effective neck cut has been completed in the dam.

3. The fetus must not be allowed to breathe air at any stage after removal of the pregnant uterus from the dam.

4. The fetus which may breathe air, or which is exposed before expiry of the 5-minute minimum waiting time after slaughter of the dam, must be stunned with a captive bolt firearm or by a blow to the head with a suitable blunt instrument.

5. Where practical, the fetus should be left in the uterus and blood collection should not begin until after the fetus is dead. 
recognized (Jayme et al., 1988), since the use of serum in cell culture has a number of disadvantages:

1. serum is an ill-defined medium supplement, and is thus an ambiguous factor in cell culture (Barnes et al., 1987)

2. serum batches display quantitative and qualitative variations in their composition, and thus may introduce a significant batch-to batch variability (Price and Gregory, 1982)

3 . serum may contain different amounts of endotoxins, haemoglobin and other adverse factors

4. serum can be a potential source of (micro)biological contaminants, such as fungi, bacteria, viruses or prions.

With the identification, cloning, and recombinant production of essential growth factors and nutrients required by different cell types, several very effective chemically defined, serum-free media have been formulated (Bottenstein et al., 1979). There are significant benefits to serum-free cell culture, including the following:

1. chemically-defined and controlled culture conditions in vitro,

2. reduced variability in qualitative and quantitative culture medium composition,

3. elimination of a potential source of (micro)biological contamination, and,

4. advantages in down-stream processing (i.e. the isolation of cell culture products),

Serum-free media are generally more cell-specific. Details of serum-free media formulations for the initiation in primary cultures of specific cell types, as well as for culturing continuous cell lines, are being published increasingly (Barnes and Sato, 1980a, 1980b; Bjare, 1992; Taub, 1990) and commercial availability is increasing (Defrancesco, 1998). Therefore, key steps towards the use or the development of a serum-free formulation for a desired cell type and/or cell line are to review the published literature, to scan commercial catalogues, and to contact other laboratories working in similar fields in order to determine whether a suitable media formulation might already exist. Further steps to develop a defined medium have been proposed (Zimmerman et al., 2000).

Growing cells in serum-free media has advantages. First, as noted above, reduction in or replacement of FBS use would reduce the number of animals required to meet the demand for this product. A prerequisite, and a consequence, of the objective of using serum-free media is the need to develop new or modify current cell and tissue culture methodology (Hartung et al., 2002). Secondly, for cell biological reasons, the high specificity of serum-free media allows the selection of certain cell types and their specific stimulation and differentiation. Unfortunately, however, the ideal general-purpose serum-free medium has not yet been developed and is almost certainly an unattainable goal.

The possibilities of serum-free culturing for different applications are discussed in the following sections.

\subsection{Serum-free medium to culture epithelial cells}

One of the alternatives to the use of animal sera is to supplement serum-free medium with plant constituents. Such an example is Prolifix, which is a new reagent of plant origin, free of human or animal proteins. It contains a molecule (GCR 1003) that has an activity similar to the one of mitogenic molecules in serum (Della Rocca et al., 1999; Short et al., 1998). It supports cell culture maintenance and proliferation, and it might therefore be used to replace FBS. Two commonly used epithelial cell lines, LLC-PK1 (porcine renal proximal tubular cell line) and Caco-2 (human colorectal adenocarcinoma cell line), were progressively adapted to a special culture medium containing 10\% Prolifix (P. Prieto: Unpublished data). After adaptation, cell cultures were characterized morphologically and functionally. Results showed that both cell lines kept their typical epithelial morphology with formation of domes when grown in conventional cell plastic culture flasks.

However, the adaptation procedure of cells is long and not easy to perform. Moreover, the growth rate of both cell lines is slower in Prolifix supplemented medium than in FBS supplemented media. Another problem encountered when the culture medium was supplemented with Prolifix was the freezing/thawing protocol: cells did not survive cryopreservation, and it was not possible to keep adapted cells in stock containers. Therefore, it is very important to optimize a protocol to cryopreserve cells that are adapted to grow in this special supplemented medium. One of the main advantages offered by this reagent of plant origin is its lower cost compared to the conventional animal serum, and the lack of animal-derived substances.

Unfortunately, the precise composition of the reagent Prolifix is not available, since there are patented components in the formulation. This problem seems to be related to most, if not all, commercially available serumfree media. However, for scientific and safety reasons, it is important to be informed about the composition (Merten, 1999). Therefore, companies that produce special media to replace animal serum should provide the precise composition of their formulations. An additional problem at the moment is that the company has stopped producing and marketing this vegetal reagent. Therefore, it is important to stress the need for reliable and sufficient commercial availability of such reagents (Jayme, 1999). Since Prolifix is a vegetal extract, the batch-to-batch variability should be evaluated. 
The preliminary work done with molecules of plant origin indicates that these reagents could be seen as a promising alternative to animal serum, at least for culturing some epithelial cell lines. However, more efforts should be put into optimizing the culture conditions when FBS is replaced by vegetal reagents in order to improve cell adaptation, cell attachment, growing rates, and freezing and thawing protocols.

\subsection{Development of serum-free media for virus production}

Developing serum-free media for large-scale production offers different challenges from those for smallscale research. For instance, problems arise because the growth of cells on micro-carriers in running medium requires strong attachment of cells to the substrate, while in small-scale research cells grow in T-flasks.

The polio vaccine production unit at the Netherlands Vaccine Institute (NVI) employs animal cells which are currently cultured in Modified Eagles Medium (MEM) supplemented with 10\% FBS (Mallard et al., 1992; van Wezel et al., 1978). Current work aims to remove animal products from vaccine production processes in accordance with European Pharmacopoeia guidelines. First, five commercially available serum-free media were tested, in order to compare these to Serum Containing Medium (SCM). Although all media supported growth in T-flasks with hardly any adaptation period, except for one medium, enough problems were encountered to start developing a new medium without animal substances (AFM) (unpublished results).

The development of this medium was carried out in collaboration with the Institute Pasteur of Tunisia (IPT), where two preliminary media were formulated. The basal media MEM and M199 were supplemented with a number of vitamins, trace minerals and significant amounts of plant protein hydrolysates. Although both preliminary formulations worked in T-flasks, the MEM-based medium showed little or no cell attachment to micro-carriers in spinner cultures. However, the M199 medium, with ferrous citrate, selenite as well as in total 6 gram/L of plant hydrolysates, showed relatively good growth. The plant hydrolysates improved the attachment properties of the cells to the micro-carriers, since without hydrolysates the cells would not attach and stretch on cytodex 1, as they did on cytodex 3, a collagen coated bead.

Adding EGF (epidermal growth factor) to the medium did not enhance growth rate, viability or the final cell density. The final batch medium enabled a cell density of about $1.4 \times 10^{6}$ cells $/ \mathrm{ml}$. In recirculation mode, the cell density increased to more than $5 \times 10^{6}$ cells $/ \mathrm{ml}$. Thus, a few compounds that were historically deemed necessary for growth were omitted from the medium, resulting in a protein-free medium.
The only complex compound still present in the new medium composition is the combination of a number of plant hydrolysates. It remains to be studied whether these protein hydrolysates are able to inhibit trypsin, or any of the other non-animal proteases under investigation to replace trypsin. Sub-cultivation and freezing-thawing protocols are influenced by the medium in which the cells were cultivated. The next step is to adapt the routine protocols to accommodate the cells grown in this largely defined basal medium.

Another example of a successful serum-free medium for large-scale production is EpiSerf (Life Technologies/ Invitrogen). It is being used for the production of influenza viruses on MDCK cells (Brands et al., 1999; Voeten et al., 1999a, 1999b). Although EpiSerf is not a total animal protein-free medium, since it contains BSA, its ease of use and grade of definition made it favourable for large scale production.

\subsection{Serum-free medium adapted cell lines}

As mentioned above, the development of a serum-free medium is the first step in the process. The second step is the adaptation of cells to the new medium. Today, there are instructions on how, as well as medium compositions available which help to adapt a cell line to a serum-free medium. Some companies have "ready-to-use" serumfree media in their product list. However, when the decision is made to change from a serum-dependent medium to a serum-free, or rather, a chemicallydefined medium, one has to go through a time-consuming procedure, where unexpected problems will frequently be encountered. In order to stimulate scientists to give up the use of FBS, a project was initiated by the FFVFF (Foundation for animal-free experiments) and the "Ligue Suisse contre la vivisection" with the aim of providing the scientific community with cell lines adapted to chemically-defined media together with easy-to-follow manuals for their cultivation.

Several culture media and working protocols are available for producing monoclonal antibodies with hybridomas. In order to generate new hybridomas from immunized mouse spleen cells and mouse myeloma cells by fusion with the aid of polyethylene glycol 1500, the two most frequently used X63-Ag8 myeloma cell lines and the hybridoma cell line $\mathrm{Sp} 2 / 0$ were adapted to the chemically fully defined "TurboDoma" medium (Marison et al., 1997; Marx et al., 1997). "Chemically fully defined" means a medium that does not contain any complex additives such as lipid mixtures, hydrolysates, peptides or proteins or other, even recombinant, growth factors. These tools allow the scientist to directly generate and select antibody-secreting hybridomas in these chemically-defined culture media. Such direct procedures prevent users from losing antibody productivity 
during the typical long-lasting adaptation to cell proliferation in serum-free media.

Another field of application in cell culture technology with potentially increasing serum demand is the stable and transient gene transfection of animal cell lines for the production of recombinant proteins. While adapting the cell line 293EBNA to "Hektor" and "InVitrus" media (Cell Culture Technologies GmbH, Buhnrain 14, $\mathrm{CH}-8052$ Zurich), the cells partially lose their ability to attach to the plastic surface of the T-flask. In addition, the adapted cell lines generally exhibit a slower growth rate. Whether this drawback can be compensated for by optimizing the composition of the current culture media (e.g. addition of a cell-line specific recombinant growth factor) is also part of the study.

Also other cell lines such as COS-1, COS-7, NS0 and the two CHO cell lines DUXB11 and DG44 (kindly provided by Prof. Lawrence Chasin, Columbia University) are currently in the adaptation phase to proliferation in a chemically-defined culture environment. The CHO-DUXB11 cell line, growing in a chemically defined minimal medium was previously reported to be useful for producing recombinant u-PA (Zang et al., 1995), whereas a CHO-K1 cell line selected for fast growth in chemically-defined media has been available since 1993 (Messi, 1993).

The final goal will be to deposit all cell lines adapted to chemically-defined media at the European Collection of Cell Cultures (ECACC) where they will be available for scientists. Whenever possible, protocols of the most suitable cultivation techniques will be provided with the cells.

\subsection{Requirements for the use of serum-free media in large-scale production}

For research purposes, there is a wide array of media and alternatives to FBS-use available. For the development and application of serum-free media in large-scale production, for instance the production of hormones and vaccines, additional requirements apply. These relate to the production processes, the end product and regulatory requirements and acceptability. The majority of biological product manufacturers favour the reduction or replacement of animal serum in cell culture media, since contamination of the end product can be avoided thereby improving the safety of the product and the standardisation of the production process. Also, the requirements regarding the screening of animal substances for potential contaminating viruses and or prions are becoming increasingly costly to implement.

Changes in cell culture medium composition in the production of registered products, are sometimes regarded as a new product by authorities, which would require elaborate re-registration procedures.
The irony is that rigid regulatory requirements discourage producers to improve the safety of the final product and/or consistency of production by eliminating substances of animal origin. A more scientific approach of regulatory authorities towards changes in medium composition, that do not affect the final product, is desirable. As such, medium changes can be viewed for what they are: minor changes in production.

Once a serum-free medium is proposed for certain cells both in research settings and for production purposes, it should be tested for compatibility with large scale cell culture purposes from the start of development. Cells used for the production of pharmaceuticals in either a serum containing or a serum-free environment should ideally perform with at least similar yields. At none of the cell culture stages, including for example the freezing/storage stage in liquid nitrogen, should a cell encounter serum, since this would render the procedure meaningless in terms of being serum-free.

More criteria that should apply to new serum-free media are:

- easily available through regular channels;

- standardized (description of components, marginal batch-to-batch variation);

- trypsin compatibility (for anchorage dependent cell cultures);

- preferentially to be used as a basal medium to which specific components can be added to enable maintenance or expansion of specific cells;

- free of "endogenous and extraneous agents" complying with European and USA Pharmacopoeia;

- Down Stream Processing should not be affected by the change in medium composition, if applicable and compatible with both GLP and GMP implementation. This would imply that the new product specification tests can be limited;

- The final product should not contain components that are not present in the registered product.

There are as yet limited choices for serum-free media or even protein-free media for the manufacturing of new products with cultured cells. Except in cases where no serum-free media are available to meet a sudden urgent need for a product, it would be preferable for authorities not to register new products manufactured in media containing serum.

The next step in the development of broadly applicable serum-free media is to further reduce the amount of animal-derived proteins (e.g. BSA) used. This would preferably be achieved by replacing these with proteins from alternative cost-effective sources. 
4.6. Requirements for the use of serum-free media in cell therapeutic use

The area of cell therapeutic use, like in vitro fertilization, depends on culture media. The fundamental demands on cell handling/culture media for cell therapeutic use are that the media should be safe, consistent, and effective.

The ideal situation would be to have chemically defined media during the whole cell-handling procedure. This is not always possible with the techniques and knowledge of today and the cost/value efficacy might make it non-viable. Serum still is one of the major constituents in culture media.

It is strongly recommended that for all human cell therapeutic use, animal derived products should be avoided. If possible, taking into account the economic perspective, the different media should also be chemically defined. This reinforces the point that all animal and human derived protein sources should be avoided.

An area, where today it is technically possible to use a chemically-defined medium with a high efficacy is the culture of human embryos for in vitro fertilization (IVF) purposes (Gardner and Lane, 1998; Gardner and Lane, 2000; Gardner et al., 2001; Gardner et al., 1999). Recombinant human albumin (r-HSA) can be used instead of purified human albumin. r-HSA is structurally identical to HSA and provides the following advantages: it is safe - free from viral and prion contamination; and it is consistent - greater homogeneity and high batch-to-batch consistency. The major disadvantage is the price, which is several times higher for r-HSA than for purified HSA.

Each cell therapy field will need to evaluate the cost/ risk ratio of the treatment when it is technically possible to have a chemically-defined medium, as in the above mentioned field.

\section{Conclusion}

In conclusion, it has been shown, without the intention to be complete, that several means exist to cultivate cells in a serum-free environment and that this is possible and successfully applied in different research areas. The methods mentioned are standardized and defined and lead to better quality assurance and reproducibility, as recommended by Good Cell Culture Practice (Hartung et al., 2002). A further reason to divert from the use of animal serum has to do with its unknown composition, possibly containing factors which could lead to non-specific binding and (in)activation (Goegan et al., 1995).

Unfortunately, the composition of commercially available serum-free media is generally unknown since producers usually do not provide that information. This information is essential for research purposes. Producers should therefore be encouraged to release the composition of these media.

Many serum-free media have been developed for a number of specific cell types, continuous cell lines and tissue culture, but information on these is not easily available. To encourage the application of serum-free media, an easily accessible database should be established with extensive information on media composition, cell types, culture systems and links to users and/or published literature. Preferably, this database should be accessible via the Internet. A first attempt was made for commercially available media (Defrancesco, 1998), but has not been followed up nor has it recently been updated. To further stimulate the development of new defined serum-free media and to encourage the exchange of information, regular symposia should be organized, involving scientists and regulators, where serum-free media, their development strategies and the effects on cells are discussed, both for small scale research as for large scale manufacturing purposes.

The process of developing serum-free media or adapting cells to serum-free media is time consuming and difficult. The development of these new media should be stimulated by the provision of resources, preferably by launching EU Framework Programs.

\section{General conclusions}

1. The collection of FBS without fetal suffering is possible, when the recommended safeguards (see recommendations) are taken into account.

2. The recommended safeguards for calf fetuses are practical and straightforward to put into effect during commercial slaughter of their dams.

3. Due to large-scale production, manufacturers may have different requirements for serum-free media formulations, compared to specific research settings.

4. Achieving regulatory acceptance of changes in production media is currently time-consuming and costly, which does not encourage the implementation of chemically-defined serum-free media.

5. Reduction of the use of FBS can be obtained by several means (see recommendations).

\section{Recommendations}

1. The fetus must be unaware (unconscious) before any invasive procedure is initiated by the act of 
cutting open the uterus to expose a part or the whole of the fetus The procedure of fetal blood collection must therefore not begin until at least 5 min after an effective neck cut has been completed in the dam

2. Not only must the fetus be unaware (unconscious, i.e. flat or iso-electric $\mathrm{EEG} / \mathrm{ECoG}$ ) before the procedure begins, its EEG/ECoG must remain flat throughout the procedure. The fetus must therefore not be allowed to breathe air at any stage after removal of the pregnant uterus from the dam.

3. The fetus which may breathe air, or which is exposed before expiry of the $5 \mathrm{~min}$ minimum waiting time after slaughter of the dam, must be stunned with a captive bolt firearm or by a blow to the head with a suitable blunt instrument.

4. The detailed safeguards noted above represent a Fetal Calf Slaughter Welfare Protocol (Table 1). FBS producers should be encouraged to adhere to this protocol and FBS users should ensure that they only purchase it from those producers who demonstrate that they adhere to this protocol.

5. Where technically possible, animal-derived components in cell-culture media should be replaced by alternative products, e.g. plant-derived or recombinant products.

6. For the purpose of standardization, FBS use in routine in vitro assays should be strongly discouraged, due to batch-to-batch variability, affecting reproducibility and robustness.

7. As the complex composition of serum may result in adverse reactions, like non-specific binding, activation and inactivation, in vitro toxicity tests should preferably be based on chemically-defined media.

8. Companies producing serum-free media for cell culture should provide information on the composition.

9. The replacement of serum for the production of registered cell-derived products is hampered by the current registration procedures. When the final products are bio-equivalent, registration authorities should regard such changes as minor, in order to encourage further development and use of chemically-defined media.

10. Serum-free media have been developed for a number of specific cell types, continuous cell lines and tissue culture. Therefore, a public database should be created with information on media composition, cell types, culture systems and links to users, for further reference.

11. More resources should be made available for the development of chemically-defined serum-free media, e.g. by launching EU Framework Programs.
12. The development of new serum-free media seems to take place more or less in isolation. Regular symposia should be organized, involving scientists and regulators, where serum-free media, their development strategies and the effects on cells are discussed, both for small scale research as for large scale manufacturing purposes.

13. As part of Good Cell Culture Practice, scientists should avoid the use of Fetal Bovine Serum and apply a fully defined medium. In cases were no alternatives are (yet) available, FBS should be obtained from a company that has a clear statement that serum was obtained according to the procedures recommended in this report

\section{References}

Anon, 2001. White paper on a strategy for a future chemicals policy. http://europa.eu.int/comm/environment/chemicals/whitepaper.htm. (acces date: 21-08-2003).

Asher, D.M., 1999. Bovine sera used in the manufacture of biologicals: current concerns and policies of the US. Food and Drug Administration regarding the transmissible spongiform encephalopathies. Developments in Biological Standardization 99, 41-44.

Bager, F., Braggins, T.J., Devine, C.E., Graafhuis, A.E., Mellor, D.J., Tavener, A., Upsdell, M.P., 1992. Onset of insensibility at slaughter in calves: effects of electroplectic seizure and exsanguination on spontaneous electrocortical activity and indices of cerebral metabolism. Research in Veterinary Science 52, 162-173.

Balls, M., Goldberg, A.M., Fentem, J.H., Broadhead, C.L., Burch, R.L., Festing, M.F., Frazier, J.M., Hendriksen, C.F., Jennings, M., van der Kamp, M.D., Morton, D.B., Rowan, A.N., Russell, C., Russell, W.M., Spielmann, H., Stephens, M.L., Stokes, W.S., Straughan, D.W., Yager, J.D., Zurlo, J., van Zutphen, B.F., 1995. The three Rs: the way forward. The report and recommendations of ECVAM Workshop 11. Alternatives To Laboratory Animals 23, 838-866.

Barnes, D., McKeehan, W.L., Sato, G.H., 1987. Cellular endocrinology: integrated physiology in vitro. In Vitro Cellular and Developmental Biology 23, 659-662.

Barnes, D., Sato, G., 1980a. Methods for growth of cultured cells in serum-free medium. Analytical Biochemistry 102, 255-270.

Barnes, D., Sato, G., 1980b. Serum-free cell culture: a unifying approach. Cell 22, 649-655.

Berger, P.J., Walker, A.M., Horne, R., Brodecky, V., Wilkinson, M.H., Wilson, F., Maloney, J.E., 1986. Phasic respiratory activity in the fetal lamb during late gestation and labour. Respiration Physiology 65, 55-68.

Bjare, U., 1992. Serum-free cell culture. Pharmacology and Therapeutics 53, 355-374.

Bottenstein, J., Hayashi, I., Hutchings, S., Masui, H., Mather, J., McClure, D.B., Ohasa, S., Rizzino, A., Sato, G., Serrero, G., Wolfe, R., Wu, R., 1979. The growth of cells in serum-free hormone-supplemented media. Methods in Enzymology 58, 94-109.

Brands, R., Visser, J., Medema, J., Palache, A.M., van Scharrenburg, G.J., 1999. Influvac: a safe Madin Darby Canine Kidney (MDCK) cell culture-based influenza vaccine. Developments in Biological Standardization 98, 93-100. discussion 111.

Clewlow, F., Dawes, G.S., Johnston, B.M., Walker, D.W., 1983. Changes in breathing, electrocortical and muscle activity in una- 
naesthetized fetal lambs with age. Journal of Physiology 341, 463476.

Cohen, S., 1987. Epidermal growth factor. In Vitro Cellular and Developmental Biology 23, 239-246.

Dawes, G.S., 1988. The 1987 James AF. Stevenson memorial lecture. The development of fetal behavioural patterns. Canadian Journal of Physiology and Pharmacology 66, 541-548.

Dawes, G.S., Fox, H.E., Leduc, B.M., Liggins, G.C., Richards, R.T., 1972. Respiratory movements and rapid eye movement sleep in the foetal lamb. Journal of Physiology 220, 119-143.

Defrancesco, L., 1998. Serum-free cell culture: From art to science in 25 years. The Scientist 12, 19-24.

Della Rocca, G.J., Maudsley, S., Daaka, Y., Lefkowitz, R.J., Luttrell, L.M., 1999. Pleiotropic coupling of $G$ protein-coupled receptors to the mitogen-activated protein kinase cascade. Role of focal adhesions and receptor tyrosine kinases. Journal of Biological Chemistry 274, 13978-13984.

Deuel, T.F., 1987. Polypeptide growth factors: roles in normal and abnormal cell growth. Annual Review of Cell Biology 3, 443-492.

Eloit, M., 1999. Risks of virus transmission associated with animal sera or substitutes and methods of control. Developments in Biological Standardization 99, 9-16.

Gardner, D.K., Lane, M., 1998. Culture of viable human blastocysts in defined sequential serum-free media. Human Reproduction 13 (Suppl. 3), 148-159. discussion 160.

Gardner, D.K., Lane, M., 2000. Recombinant human serum albumin and hyaluronan can replace blood-derived albumin in embryo culture media. Fertility and Sterility 74, S31.

Gardner, D.K., Lane, M., Maybach, J.M., Hasler, J.M., 2001. Bovine oocyte maturation in a completely defined medium: replacing serum with recombinant albumin and hyaluronan. Theriogenology 55, 471.

Gardner, D.K., Rodriegez-Martinez, H., Lane, M., 1999. Fetal development after transfer is increased by replacing protein with the glycosaminoglycan hyaluronan for mouse embryo culture and transfer. Human Reproduction 14, 2575-2580.

Goegan, P., Johnson, G., Vincent, R., 1995. Effects of Serum Protein and Colloid on the AlamarBlue Assay in Cell Cultures. Toxicology In Vitro 9, 257-266.

Gregory, N.G., 1998. Animal welfare and meat science. CAB International Publishing, Wallingford. Oxon, UK.

Gregory, N.G., Wilkins, L.J., 1984. Effect of cardiac arrest on susceptibility to carcass bruising in sheep. Journal of Science of Food and Agriculture 35, 671-676.

Gregory, N.G., Wotton, S.B., 1984. Sheep slaughtering procedures. II. Time to loss of brain responsiveness after exsanguination or cardiac arrest. British Veterinary Journal 140, 354-360.

Harding, R., Poore, E.R., Cohen, G.L., 1981. The effect of brief episodes of diminished uterine blood flow on breathing movements, sleep states and heart rate in fetal sheep. Journal of Developmental Physiology 3, 231-243.

Hartung, T., Balls, M., Bardouille, C., Blanck, O., Coecke, S., Gstraunthaler, G., Lewis, D., 2002. Good Cell Culture Practice. ECVAM Good Cell Culture Practice Task Force Report 1. Alternatives To Laboratory Animals 30, 407-414.

Hodgson, J., 1995. To treat or not to treat: that is the question for serum. Bio/Technology 13, 333-334. 337-338, 342-333.

Jayme, D.W., 1999. An animal origin perspective of common constituents of serum-free medium formulations. Developments in Biological Standardization 99, 181-187.

Jayme, D.W., Epstein, D.A., Conrad, D.R., 1988. Fetal bovine serum alternatives. Nature 334, 547-548.

Jochems C.E., 1997. Use, trade and harvest of livestock sera. http:// www.nca-nl.org/English/Docs/fcreport.doc, (acces date: 21-082003).

Jochems, C.E., van der Valk, J.B., Stafleu, F.R., Baumans, V., 2002. The use of fetal bovine serum: ethical or scientific problem? Alternatives To Laboratory Animals 30, 219-227.
Karasawa, H., Sakaida, K., Noguchi, S., Hatayama, K., Naito, H., Hirota, N., Sugiyama, K., Ueno, J., Nakajima, H., Fukada, Y., Kin, H., 2001. Intracranial electroencephalographic changes in deep anesthesia. Clinical Neurophysiology 112, 25-30.

Kohlpoth, M., Rusche, B., 1997. Kultivierung einer permanenten Fischzellinie in serumfreien Medien: Spezielle Erfahrungen mit einem Zytotoxizitätstest für Abwasserproben. Alternatieven zu Tierexperimenten 14, 16-20.

Kyriakis, J.M., Avruch, J., 2001. Mammalian mitogen-activated protein kinase signal transduction pathways activated by stress and inflammation. Physiological Reviews 81, 807-869.

Levi-Montalcini, R., 1987. The nerve growth factor: thirty-five years later. EMBO Journal 6, 1145-1154.

Levinger, I.M., 1995. Shechita in the light of the year 2000: a critical review of the scientific aspects of methods of slaughter and shechita. Maskil L'David, Jerusalem, Israel.

Luft, A.R., Buitrago, M.M., Paul, J.S., Hagan, J., Ding, M.C., Thakor, N., Hanley, D.F., 2002. Early restitution of electrocorticogram predicts subsequent behavioral recovery from cardiac arrest. Journal of Clinical Neurophysiology 19, 540-546.

Mallard, E.C., Gunn, A.J., Williams, C.E., Johnston, B.M., Gluckman, P.D., 1992. Transient umbilical cord occlusion causes hippocampal damage in the fetal sheep. American Journal of Obstetrics and Gynecology 167, 1423-1430.

Marison I., Stoll T.S., Lüllau E. von Stockar U., 1997. Factors affecting the production and quality of IgA antibodies against V. cholerae. In M. J. T. Carrondo, J. B. Griffiths J. L. P. Moreira (Eds.), Animal cell technology: From vaccines to genetic medicine. Kluwer Academic Publishers, Dordrecht, The Netherlands.

Marx, U., Embleton, M.J., Fischer, R., Gruber, F.P., Hansson, U., Heuer, J., de Leeuw, W.A., Logtenberg, T., Merz, W., Portetelle, D., Romette, J.-L., Straughan, D.W., 1997. Monoclonal antibody production. Alternatives To Laboratory Animals 25, 121-137.

Maurer H., 1986. Towards chemically-defined, serum-free media for mamalian cell culture. In R. Freshney (Eds.), Animal cell culture: A practical approach. IRL Press, Oxford.

Mellor D.J., 2003. Guidelines for the humane slaughter of the fetuses of pregnant ruminants. Surveillance 30, 26-28.

Mellor, D.J., Gregory, N.G., 2003. Responsiveness, behavioural arousal and awareness in fetal and newborn lambs: experimental, practical and therapeutic implications. New Zealand Veterinary Journal 51, 2-13.

Merten, O.W., 1999. Safety issues of animal products used in serumfree media. Developments in Biological Standardization 99, 167-180.

Messi, F., 1993. Serum- und proteinfrei wachsende Zellen. EPA 0653 $487 \mathrm{~A} 1$.

Mott, J.C., 1961. The ability of young mammals to withstand oxygen lack. British Medical Bulletin 17, 144-148.

Newhook, J.C., Blackmore, D.K., 1982. Electroencephalographic studies of stunning and slaughter of sheep and calves. Part 2. Meat Science 6, 295-300.

Price, P.J., Gregory, E.A., 1982. Relationship between in vitro growth promotion and biophysical and biochemical properties of the serum supplement. In Vitro 18, 576-584.

Rigatto, H., Lee, D., Davi, M., Moore, M., Rigatto, E., Cates, D., 1988. Effect of increased arterial CO2 on fetal breathing and behavior in sheep. Journal of Applied Physiology 64, 982-987.

Russell W. Burch R., 1959. The principles of humane experimental technique. Methuen, London.

Shah, G., 1999. Why do we still use serum in the production of biopharmaceuticals? Developments in Biological Standardization 99, $17-22$.

Short, S.M., Talbott, G.A., Juliano, R.L., 1998. Integrin-mediated signaling events in human endothelial cells. Molecular Biology of the Cell 9, 1969-1980.

Taub, M., 1990. The use of defined media in cell and tissue culture. Toxicology In Vitro 4, 213-225. 
UFAW, 1987. Humane slaughter of animals for food. Universities federation for animal welfare, Potters Bar, UK.

van Wezel, A.L., van Steenis, G., Hannik, C.A., Cohen, H., 1978. New approach to the production of concentrated and purified inactivated polio and rabies tissue culture vaccines. Developments in Biological Standardization 41, 159-168.

Voeten, J.T., Brands, R., Palache, A.M., van Scharrenburg, G.J., Rimmelzwaan, G.F., Osterhaus, A.D., Claas, E.C., 1999a. Characterization of high-growth reassortant influenza A viruses generated in MDCK cells cultured in serum-free medium. Vaccine 17, 1942-1950.

Voeten, J.T., Claas, E.C., Brands, R., Palache, A.M., van Scharrenburg, G.J., Rimmelzwaan, G.F., Osterhaus, A.D., 1999 b. Generation and characterization of reassortant influenza A viruses propagated in serum-free cultured MDCK-SF1 cells. Developments in Biological Standardization 98, 77-87. discussion 8990 .
Warriss, P.D., 1984. Exsanguination of animals at slaughter and the residual blood content of meat. Veterinary Record 115, 292-295.

Wessman, S.J., Levings, R.L., 1999. Benefits and risks due to animal serum used in cell culture production. Developments in Biological Standardization 99, 3-8.

Widman, C., Gibson, S., Jarpe, M.B., Johnson, G.L., 1999. Mitogenactivated protein kinase: Conservation of a three-kinase module from yeast to human. Physiological Reviews 79, 143-180.

Worth A.P. Balls M., 2002. Alternative (non-animal) methods for chemicals testing: Current status and future prospects.

Zang, M., Trautmann, H., Gandor, C., Messi, F., Asselbergs, F., Leist, C., Fiechter, A., Reiser, J., 1995. Production of of recombinant proteins in chinese hamster ovary cells using a protein-free cell culture medium. Bio/Technology 13, 389-392.

Zimmerman, A.M., Vierck, J.L., O'Reilly, B.A., Dodson, M.V., 2000. Formulation of a defined medium to maintain cell health and viability in vitro. Methods in Cell Science 22, 43-49. 